\title{
Fatigue Strength of Natural Materials
}

\author{
A. A. Berlin* \\ Semenov Institute of Chemical Physics, Russian Academy of Sciences, Moscow, 119991 Russia \\ *e-mail: berlin@chph.ras.ru \\ Received February 6, 2019; revised February 26, 2019; accepted March 18, 2019
}

\begin{abstract}
Fundamental problems associated with new directions in the development of composite materials are considered.
\end{abstract}

Keywords: fatigue strength, materials, deformation

DOI: $10.1134 / \mathrm{S} 1995421220010062$

Nature and human beings solve a number problems of material strength in the following ways.

(i) The combination of high short-term strength and high fracture toughness (absence of brittleness) is overcome by the creation of fibrous and layer composites.

Artificial materials usually work for a long time (have high fatigue strength) in the field of elastic deformations, and the operation boundaries are within the limits of elasticity.

(ii) The combination of high fatigue strength for large deformations is overcome by creation of composites with fluids or elastomers (bones, joints, the spine, and muscles in human beings and animals, and solid fiber with liquid sap in trees).

Why?

Large deformations of a solid (below $T_{\mathrm{g}}$ or $T_{\mathrm{m}}$ ), high rigidity, elastic modulus, i.e., plastic deformation, always (?) lead to the accumulation of defects (dislocations in crystalline bodies, dilatation in glasses, crazes in polymers, etc.) and subsequent fracture; i.e., they have low fatigue strength at large deformations (higher than the elastic limit).

In liquids or elastomers (above $T_{\mathrm{g}}$ or $T_{\mathrm{m}}$ ), these defects do not form or quickly relax back to the normal state.

Therefore, for the implementation of large deformations in combination with high rigidity, various combinations are realized in nature.

For example, bones are connected by joints in which large shear deformations occur in a fluid lubricant.

For trees (which are living things), large deformations (bending of branches) are possible while liquid sap is contained within them. A dried branch becomes brittle and easily breaks when bending. Liquid sap in a tree is water in a complex (eutectics) with other substances (for example, arabinogalactan, etc.). The freezing temperature of such complexes can be significantly lower than $0^{\circ} \mathrm{C}$; therefore, trees (for example, larch) can exist normally and not break in the wind even in Siberian frosts.

\section{REFERENCES}

1. Al. Al. Berlin, M. A. Mazo, and N. K. Balabaev, "The nature of defects arising from plastic deformation of glasses," Vse Mater., Entsikl. Sprav., No. 10, 10-13 (2012).

2. Al. Al. Berlin and M. A. Mazo, "Melting and vitrification of Lennard-Jones spheres," Polym. Sci., Ser. D 6 (3), 228-231 (2013).

3. I. A. Strelnikov, M. A. Mazo, N. K. Balabaev, E. F. Oleinik, and A. A. Berlin, "Energy storage in plastic deformation of glassy polymethylene," Dokl. Phys. Chem. 457 (1), 108-111 (2014).

4. Al. Al. Berlin, M. A. Mazo, I. A. Strel'nikov, and N. K. Balabaev, "Modeling of plastic deformation of glasses in creeping and stress relaxation regimes," Polym. Sci., Ser. D 8 (2), 85-91 (2015).

5. Al. Al. Berlin, L. Rotenburg, and R. Baserst, "Strain behavior and glass-liquid transition in granular systems," Khim. Fiz. 10 (9), 1284-1291 (1991).

6. Al. Al. Berlin, L. Rotenburg, and R. Baserst, "Features of the deformation of disordered polymer and nonpolymer bodies," Vysokomol. Soedin., Ser. A 34 (7), 6-32 (1992).

7. M. A. Mazo, I. A. Strel'nikov, L. I. Manevich, and A. A. Berlin, "Analysis of structural-dynamic inhomogeneities of an amorphous system: Two-dimensional systems of Lennard-Jones disks," Entsikl. Inzh.-Khim., No. 9, 23-33 (2010).

Translated by V. Avdeeva 